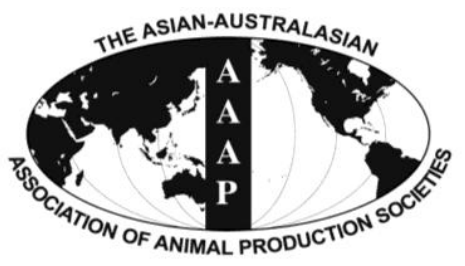

Asian-Aust. J. Anim. Sci.

Vol. 25, No. $8: 1159$ - 1168

August 2012

www.ajas.info

http://dx.doi.org/10.5713/ajas.2012.12090

\title{
Growth Performance, Meat Yield, Oxidative Stability, and Fatty Acid Composition of Meat from Broilers Fed Diets Supplemented with a Medicinal Plant and Probiotics
}

\author{
Md. Elias Hossain, Gwi Man Kim, Sung Ki Lee ${ }^{1}$ and Chul Ju Yang* \\ Department of Animal Science and Technology, Sunchon National University, Suncheon, Jeonnam 540-742, Korea
}

\begin{abstract}
The experiment was carried out to investigate the effects of Alisma canaliculatum with probiotics (ACP) on the growth performance, meat composition, oxidative stability, and fatty acid composition of broiler meat. Sixteen probiotic strains were tested for their levels of acid, bile, and heat tolerance. Among them, Lactobacillus acidophilus KCTC 3111, Enterococcus faecium KCTC 2022, Bacillus subtilis KCTC 3239, and Saccharomyces cerevisiae KCTC 7928 were selected for use in ACP. Exactly 140 Ross broiler chicks were assigned to four dietary treatments in five replications for $5 \mathrm{wks}$ in a completely randomized design. The dietary treatments were NC (Negative control; basal diet), PC (Positive control; basal diet with 0.005\% Chlortetracycline), ACP-0.5\% (basal diet with $0.5 \%$ ACP powder), and ACP-1\% (basal diet with $1 \%$ ACP powder). According to the results, body weight of the broilers increased, and feed conversion ratio improved in the ACP- $0.5 \%$ group compared to the NC group $(\mathrm{p}<0.05)$. Crude protein content of breast meat was higher $(\mathrm{p}<0.05)$ in the ACP-0.5\% group, whereas crude fat content of thigh meat was lower $(\mathrm{p}<0.05)$ in the supplemented groups. Breast meat absolute and relative weights were both higher $(\mathrm{p}<0.05)$ in the ACP groups compared to the control group. Further, ACP diets increased gizzard and decreased large intestine relative weights, whereas kidney relative weight decreased upon the addition of a higher level (1\%) of ACP $(p<0.05)$. Thiobarbituric acid reactive substances values of breast and thigh meats were reduced $(p<0.05)$ by ACP supplementation compared to control. Regarding the fatty acid composition of breast meat, arachidonic acid, docosahexaenoic acid, PUFA, and $n 6$ fatty acid levels decreased $(\mathrm{p}<0.05)$ in the ACP groups, whereas the levels of linoleic acid, PUFA, PUFA/SFA, and n6 fatty acid in thigh meat decreased $(\mathrm{p}<0.05)$ by ACP and PC diets. It can be suggested based on the study results that ACP- $0.5 \%$ diet could be an effective feed additive for broilers. (Key Words: Alisma canaliculatum, Probiotics, Growth, Meat, Broiler)
\end{abstract}

\section{INTRODUCTION}

Alisma canaliculatum A. Br. et Bouche (AC), a member of the plant family Alismataceae, is an herb commonly used in traditional Korean medicine. Alisma is called water plantain, or taeksa in Korea. Ever since the ban on adding antibiotics to animal feed, producers have sought alternative natural feedstuffs to meet the industry demands. Alisma has diuretic (Kang et al., 2006), hepatoprotective (Hong et al., 2006), antitumor (Huang et al., 2006), and antibacterial effects on Escherichia coli (Mikamo et al., 1998). Rhizoma Alismatis, which is dried tuber of AC, is the main medicinal part of the plant. Previous studies have shown that this part contains protostane triterpenes (Matsuda et al., 1999; Peng

\footnotetext{
* Corresponding Author: Chul Ju Yang. Tel: +82-61-750-3235, Fax: +82-61-750-3239, E-mail: yangcj@ scnu.kr

1 Suncheon Gwangyang Livestock Co-operative, Yeonhyangdong, Suncheon, Jeonnam, Korea.

Submitted Feb. 17, 2012; Accepted May 2, 2012; Revised May 9, 2012
}

et al., 2002) such as alisol A, B, C, and its monoacetates, guaiane sesquiterpenes (Yoshikawa et al., 1994; Peng et al., 2003) such as alismols A, B, and C, and kaurane diterpenes (Nakajima et al., 1994; Peng and Lou, 2002).

The butanol fraction of AC has been shown to reduce the levels of blood glucose, plasma triglycerides, free fatty acids, and cholesterol in streptozotocin-induced diabetic rats (Kim, 2003). In addition, the butanol fraction of AC was found to reduce peroxidative liver damage in streptozotocin-induced diabetic rats (Choi, 2004). Antioxidant and antidiabetic activities of AC were also observed in rats (Choe, 2008). Protostane-type triterpenoids have been shown to inhibit the effects of type I-IV allergies in experimental models (Kubo et al., 1997), block nitric oxide production (Matsuda et al., 1999), and display anticomplementary activities (Lee et al., 2003). Further, methanol extract of $A$. orientale rhizome has been shown to enhance the activities of hepatic antioxidant enzymes such as epoxide hydrolase and glutathione S-transferase in 
bromobenzene-treated rats (Hur et al., 2007).

Probiotics consist of various types of microorganisms that improve gut microflora and affect both the local and systemic immune systems by secreting beneficial enzymes, organic acids, vitamins, and nontoxic antibacterial substances upon ingestion (Jun et al., 2002). Microbial species that have been used as probiotics include species of Bacillus, Bifidobacterium, Enterococcus, E. coli, Lactobacillus, Lactococcus, Streptococcus, a variety of yeast species, and undefined mixed cultures (Simon et al., 2001). These groups differ from each other in their properties, origin, and mode of action. The advantages of probiotics include improved general health, feed conversion ratios, and growth rates, as well as increased disease resistance, milk yield, and egg production (Fuller, 1992; Ahmad, 2006; Guerra et al., 2007; Mountzouris et al., 2007). Previous investigations into the modes of action of phytobiotic substances and probiotic strains have demonstrated the possibility of synergism between these classes of compounds and animal performance. Kim et al. (2007) suggested that plant extracts and Lactobacillus spp. could be used as alternatives to antibiotic growth promoters for improvement of the growth performance of broiler chicks. Sarker et al. (2010b) reported that fermented green tea improves weight gain and has no negative effect on the blood profile of post weaning Hanwoo calves. Kim et al. (2010) studied medicinal plants with probiotics and concluded that A. canaliculatum, Viscum album, and Cornus officinalis with probiotics could be used as replacements for antibiotics to increase the growth performance and immune response of growing pigs. In a broiler experiment, Hossain et al. (2011a) noted that $A$. canaliculatum probiotics exhibit high tolerance to acid, bile, and heat, inhibit E. coli proliferation, and have no adverse effects on broiler performance. Based on these observations, this experiment was designed to evaluate the effects of $A$. canaliculatum with probiotic strains (ACP) on the growth performance, carcass composition, meat yield, fatty acid composition, and oxidative stability of broiler meat.

\section{MATERIALS AND METHODS}

\section{Selection of microbial strains and preparation of plant probiotics}

Microbial strains selection: A total of 16 strains, including Lactobacillus acidophilus, L. plantarum, Enterococcus faecium, Bacillus subtilis, B. coagulans, and Saccharomyces cerevisiae were used as candidate probiotic strains. These microbes are a part of the Korean Collection for Type Cultures (KCTC) and were obtained from the Korea Research Institute of Bioscience and Biotechnology. The culture media for the experimental strains were de Man,
Rogosa, and Sharpe (MRS) medium (Difco, Detroit, MI, USA) for Lactobacillus spp., nutrient broth (NB) medium (Difco) for Bacillus spp., and yeast and mold (YM) medium (Difco) for yeast. To test the acid tolerance levels of the strains, simulated gastric juice was made according to a slightly altered method of Kobayashi et al. (1974). Experimental strains were injected into sterilized broth media $(50 \mathrm{ml})$ and then cultivated at $37^{\circ} \mathrm{C}$ for $48 \mathrm{~h}$. Each strain $(1 \mathrm{ml})$ was inoculated into simulated gastric juice consisting of NB medium containing 1,000 U of pepsin/ml adjusted to $\mathrm{pH} 3$ using $1 \mathrm{~N} \mathrm{HCl}(50 \mathrm{ml})$ and also into sterilized NB medium adjusted to $\mathrm{pH} 7(50 \mathrm{ml})$ as a control. Lactobacillus spp. and Bacillus spp. were incubated at $37^{\circ} \mathrm{C}$ and yeast at $30^{\circ} \mathrm{C}$ for $3 \mathrm{~h}$. Serial decimal dilutions in MRS agar medium for Lactobacillus spp., NB medium for Bacillus spp., and YM agar medium for yeast were prepared, after which aliquots $(1 \mathrm{ml})$ from the dilutions were spotted onto MRS, NB, or YM agar plates for the purpose of determining the number of surviving cells. Each determination was done in triplicate. Bile tolerance was measured according to a slightly altered method of Park (1999). Briefly, $1 \mathrm{ml}$ of inoculation liquid of each strain was injected into sterilized NB medium with $0.3 \%$ hog bile acid or NB medium without hog bile acid as a control. To count cells displaying bile acid tolerance, the same methods as those used to measure acid tolerance. Only those experimental strains confirmed to possess strong acid and bile tolerance in the initial tests were selected for heat tolerance testing. Heat tolerance was tested according to a slightly altered method of You et al. (2005). Lactobacillus spp. and Bacillus spp. were treated with heat at $80^{\circ} \mathrm{C}$ for 15 min, whereas yeast was treated at $70^{\circ} \mathrm{C}$ for $5 \mathrm{~min}$. Heattolerant cells were counted by following the same method used for the acid tolerance test.

Production of ACP: Strains selected according to their acid, bile, and heat tolerance were used for the preparation of ACP. Defatted rice bran and wheat bran, which are typically used in industry, were used as fermented solid media (Lee, 2006). The ACP was produced as follows: $L$. acidophilus KCTC 3111 and E. faecium KCTC 2022 were added to media containing $20 \%$ AC dried rhizome powder, $60 \%$ defatted rice bran, and $20 \%$ wheat bran. The cultures were then fermented using a commercial fermenter (W1000; Wonbalhyo Industry Co., Icheon, South Korea) at $40^{\circ} \mathrm{C}$ for $2 \mathrm{~d}$ with repeating cycles of $5 \mathrm{~h}$ of standing and 3 h of shaking. A second inoculation with B. subtilis KCTC 3239 and $S$. cerevisiae KCTC 7928 was performed, and the fermentation process was continued for $3 \mathrm{~d}$. The number of cells in ACP was also measured. The ACP (1 g) was diluted with sterilized distilled water $(10 \mathrm{ml})$ at room temperature for approximately $10 \mathrm{~min}$, after which $1 \mathrm{ml}$ was serially diluted 10 -fold in $0.85 \% \mathrm{NaCl}$ solution, cultured, and the 
number of colonies counted. All proximate components were determined by the method of AOAC (2000). The number of microorganisms and chemical composition of ACP are shown in Table 1.

\section{Measurements and analyses}

Experimental design, birds, and diets: The experimental procedures used in this study were carried out under the guidelines of the animal policy of Sunchon National University, South Korea. A total of 140-d-old straight-run Ross broiler chicks were housed in a close, ventilated caged-broiler house in which they were raised for $24 \mathrm{~h}$ of daily light. The chicks assigned to four dietary treatments in five replications with seven birds per replication for a period of $35 \mathrm{~d}$, following a completely randomized design. The dietary treatment groups were NC (Negative control; basal diet), PC (Positive control; basal diet with $0.005 \%$ Chlortetracycline), ACP-0.5\% (basal diet with $0.5 \%$ ACP powder), and ACP-1\% (basal diet with $1 \%$ ACP powder). Chlortetracycline $(0.005 \%)$ was added to the basal diets at the expense of corn, whereas ACP $(0.5 \%$ or $1 \%)$ was added to the basal diets by equally replacing corn and soybean meal. All birds received a starter diet from 0 to 3 wks and a finisher diet from 4 to $5 \mathrm{wks}$. All diets were formulated to meet or exceed the nutrient requirements of broiler chickens (National Research Council, 1994; Ross Broiler Nutrition Supplement, 2009). The ingredients composition and estimated nutrient contents of the basal diets are shown in Table 2 .

Growth performance, meat composition, internal organ development, and meat yield: Body weights were measured on a weekly basis from the initial day to the final day of the experiment. Feed intake was determined by measuring feed residue on a weekly basis from the beginning of the experiment. Feed conversion ratio (FCR) was obtained by

Table 1. The number of microbial strains in ACP and chemical compositions of $\mathrm{AC}$ and $\mathrm{ACP}$

\begin{tabular}{|c|c|c|}
\hline \multicolumn{2}{|l|}{ Microbial strains in ACP } & $\begin{array}{l}\text { Microbes number } \\
\quad(\mathrm{cfu} / \mathrm{g})\end{array}$ \\
\hline \multicolumn{2}{|c|}{ Lactobacillus acidophilus KCTC 3111} & $2.6 \times 10^{7}$ \\
\hline \multicolumn{2}{|c|}{ Enterococcus faecium KCTC 2022} & $2.0 \times 10^{8}$ \\
\hline \multicolumn{2}{|c|}{ Bacillus subtilis KCTC 3239} & $2.3 \times 10^{8}$ \\
\hline \multicolumn{2}{|c|}{ Saccharomyces cerevisiae KCTC 7928} & $3.6 \times 10^{8}$ \\
\hline $\begin{array}{l}\text { Chemical composition } \\
\text { (\% dry matter) }\end{array}$ & $\mathrm{AC}$ & $\mathrm{ACP}$ \\
\hline Moisture & 7.86 & 12.61 \\
\hline Crude protein & 22.79 & 17.95 \\
\hline Crude fat & 6.03 & 6.29 \\
\hline Crude fiber & 5.12 & 3.79 \\
\hline Crude ash & 3.95 & 4.82 \\
\hline
\end{tabular}

$\mathrm{AC}=$ Alisma canaliculatum $; \mathrm{ACP}=$ Alisma canaliculatum with probiotics
Table 2. Feed ingredients and chemical compositions of the broiler basal diets

\begin{tabular}{lcc}
\hline Ingredients (\%) & $\begin{array}{c}\text { Starter } \\
(0 \text { to } 3 \mathrm{wk})\end{array}$ & $\begin{array}{c}\text { Finisher } \\
\text { (4 to 5 wk) }\end{array}$ \\
\hline Corn grain & 57.58 & 59.96 \\
Soybean meal & 26.59 & 25.49 \\
Corn gluten & 5.00 & 4.24 \\
Soybean oil & 2.20 & 1.55 \\
Animal fats & 4.50 & 5.00 \\
Salt & 0.25 & 0.25 \\
Dicalcium phosphate & 2.14 & 2.0 \\
Limestone & 0.92 & 0.88 \\
Vitamin-mineral premix ${ }^{1}$ & 0.30 & 0.30 \\
Choline & 0.08 & 0.07 \\
L-lysine & 0.24 & 0.16 \\
Methionine & 0.20 & 0.10 \\
Calculated composition $(\%$ dry matter) & \\
Crude protein & 22.10 & 20.30 \\
Crude fat & 4.00 & 4.50 \\
Crude ash & 7.80 & 8.00 \\
Crude fiber & 6.00 & 6.23 \\
Methionine & 0.61 & 0.55 \\
Calcium & 0.83 & 0.77 \\
Available phosphorus & 0.55 & 0.51 \\
ME (kcal/kg) & 3,110 & 3,175 \\
\hline Provided & & \\
\hline
\end{tabular}

${ }^{1}$ Provided the following nutrients per kg of diet: vitamin A, 6,000 IU; vitamin $\mathrm{D}_{3}, 800 \mathrm{IU}$; vitamin $\mathrm{E}, 20 \mathrm{IU}$; vitamin $\mathrm{K}_{3}, 2 \mathrm{mg}$; thiamin, $2 \mathrm{mg}$; riboflavin, $4 \mathrm{mg}$; vitamin $\mathrm{B}_{6}, 2 \mathrm{mg}$; vitamin $\mathrm{B}_{12}, 1 \mathrm{mg}$; pantothenic acid, $11 \mathrm{mg}$; niacin, $10 \mathrm{mg}$; biotin, $0.02 \mathrm{mg}$; Cu, $21 \mathrm{mg}$; Fe, $100 \mathrm{mg}$; Zn, 60 $\mathrm{mg}$; Mn, $90 \mathrm{mg}$; I, $1.0 \mathrm{mg}$; Co, $0.3 \mathrm{mg}$ and Se, $0.3 \mathrm{mg}$.

dividing the feed intake by body weight gain. At the end of the experiment, three broilers per replication were slaughtered and samples collected. Organ development was determined by calculating the weights of the individual organs with respect to body weight. Breast and thigh meat absolute weights were also measured and their relative weights (percent to the body weight) calculated. Moisture, crude protein, crude fat, and ash percentage of the meat samples were analyzed according to the AOAC (2000).

Oxidative stability and fatty acid composition of meat: For determination of the oxidative stability of broiler breast and thigh meats, meat samples were preserved in a refrigerator at $4.5^{\circ} \mathrm{C}$, and thiobarbituric acid reactive substances (TBARS) values of meat were assayed when fresh as well as at 1 and 2 wks according to the method of Sarker and Yang (2011). TBARS values are expressed as micromoles of malondialdehyde (MDA) per $100 \mathrm{~g}$ of meat sample. Breast and thigh meat fatty acids were determined by the methyl ester extraction method according to Yang et al. (2003), and fatty acids were identified by matching their retention times with those of their relative standards (Polyunsaturated fatty acid-2, Animal Source, SUPELCO, 
Bellefonte, PA, USA) as well as the Food Composition Table (NRLSI, 2002).

\section{Statistical analysis}

All data were analyzed using the GLM procedure of SAS Institute Inc. (2003). Microbial numbers were logarithmically transformed $\left(\log _{10} \mathrm{cfu} / \mathrm{ml}\right.$ or $\log _{10} \mathrm{cfu} / \mathrm{g}$ ) before analysis. For the other parameters, data were analyzed to estimate variance components for a completely randomized design. Duncan's multiple range tests were used to examine significant differences among the treatment means. All data are presented as mean \pm SE. The level of statistical significance was preset at $\mathrm{p}<0.05$.

\section{RESULTS AND DISCUSSION}

\section{Growth performance}

Dietary supplementation of ACP affected the growthrelated performance of broilers. Data shown in the Table 3 revealed that final body weight and body weight gain at the finisher and total periods were higher $(\mathrm{p}<0.05)$ in the ACP$0.5 \%$ group compared to the $\mathrm{NC}$ and $\mathrm{ACP}-1 \%$ groups. The ACP- $0.5 \%$ group also consumed higher amounts of $(\mathrm{p}<0.05)$ feed at the finisher and total periods compared to that of the ACP-1\% group. Higher FCR was observed in the $\mathrm{PC}$ and $\mathrm{ACP}-0.5 \%$ groups at the finisher period, but when considering the total period, the ACP- $0.5 \%$ group had a higher FCR compared to the NC group $(\mathrm{p}<0.05)$.

$\mathrm{AC}$ is not regularly used in the livestock industry. Accordingly, previous studies have mainly focused on its diuretic and hepatoprotective effects in laboratory animals.
Recently, there have been attempts to evaluate their effects on pig and broiler nutrition. Body weight is commonly used to monitor the nutritional status and growth of animals (Ndlovu et al., 2007). Supplementation of ACP at $0.5 \%$ to the basal diet increased body weight gain and improved FCR of broilers in this study, which indicates that there may be a synergistic effect between the AC components and probiotic metabolites. The level of feed consumption is a basic and important factor that determines the rate of growth and body composition achieved by animals throughout their lifecycles (Richards, 2003). The decrease in feed intake as well as weight gain could be due to reduced palatability of the experimental diet following the addition of a higher level $(1 \%)$ of ACP. Hossain et al. (2011a) and Sarker et al. (2010a) found no negative effect in body weight gain and FCR when broiler was treated with ACP at $0.5 \%$. Moreover, the butanol fraction of $A$. canaliculatum with selenium has been shown to increase the body weight of streptozotocin-induced diabetic rats (Kim, 2003). In contrast, Kim et al. (2011) reported a poor FCR in AC (0.5\%)-fed broilers during the finishing period. The results of phytobiotic and probiotic application to broiler diets are not completely consistent. Some researchers have reported significant positive effects on performance (Cross et al., 2007; Mountzouris et al., 2010), whereas another group reported no influence on weight gain, feed consumption, or feed efficiency (Priyankarage et al., 2003; Sarker and Yang, 2011). In summary, researchers have mainly found that these groups of additives have great potential, but the right combination and doses have yet to be determined.

Table 3. Effect of Alisma canaliculatum with probiotics on growth performance of broilers

\begin{tabular}{|c|c|c|c|c|}
\hline \multirow{2}{*}{ Parameter } & \multicolumn{4}{|c|}{ Treatments } \\
\hline & $\mathrm{NC}$ & $\mathrm{PC}$ & ACP- $0.5 \%$ & ACP-1\% \\
\hline \multicolumn{5}{|l|}{ Body weight (g/bird) } \\
\hline Day old & $43.63 \pm 0.27$ & $43.44 \pm 0.26$ & $43.07 \pm 0.19$ & $43.32 \pm 0.21$ \\
\hline $3 \mathrm{rd} \mathrm{wk}$ & $917.32 \pm 20.66$ & $940.16 \pm 10.38$ & $954.63 \pm 17.29$ & $912.72 \pm 17.61$ \\
\hline 5 th wk & $1,637.88^{\mathrm{b}} \pm 74.91$ & $1,761.38^{\mathrm{ab}} \pm 69.88$ & $1,895.66^{\mathrm{a}} \pm 51.05$ & $1,626.23^{\mathrm{b}} \pm 53.61$ \\
\hline \multicolumn{5}{|c|}{ Body weight gain (g/bird) } \\
\hline Starter (0 to $3 \mathrm{wk})$ & $873.69 \pm 20.92$ & $896.72 \pm 10.14$ & $911.56 \pm 17.77$ & $869.41 \pm 17.58$ \\
\hline Finisher (4 to $5 \mathrm{wk}$ ) & $720.57^{\mathrm{b}} \pm 65.17$ & $821.22^{\mathrm{ab}} \pm 60.99$ & $941.04^{\mathrm{a}} \pm 46.68$ & $713.51^{\mathrm{b}} \pm 51.07$ \\
\hline Total ( 0 to $5 \mathrm{wk})$ & $1,594.25^{\mathrm{b}} \pm 75.04$ & $1,717.94^{\mathrm{ab}} \pm 69.72$ & $1,852.60^{\mathrm{a}} \pm 50.95$ & $1,582.92^{\mathrm{b}} \pm 53.75$ \\
\hline \multicolumn{5}{|l|}{ Feed intake (g/bird) } \\
\hline Starter (0 to $3 \mathrm{wk})$ & $1,255.91 \pm 25.01$ & $1,286.38 \pm 16.69$ & $1,299.50 \pm 15.89$ & $1,272.91 \pm 15.96$ \\
\hline Finisher (4 to $5 \mathrm{wk}$ ) & $1,521.59^{\mathrm{ab}} \pm 93.20$ & $1,583.66^{\mathrm{ab}} \pm 111.68$ & $1,751.85^{\mathrm{a}} \pm 42.34$ & $1,382.66^{\mathrm{b}} \pm 66.41$ \\
\hline Total ( 0 to $5 \mathrm{wk})$ & $2,777.50^{\mathrm{ab}} \pm 110.21$ & $2,870.03^{\mathrm{ab}} \pm 125.69$ & $3,051.36^{\mathrm{a}} \pm 51.11$ & $2,655.57^{\mathrm{b}} \pm 67.42$ \\
\hline \multicolumn{5}{|c|}{ Feed conversion ratio (feed/gain) } \\
\hline Starter (0 to $3 \mathrm{wk})$ & $1.44 \pm 0.01$ & $1.44 \pm 0.01$ & $1.43 \pm 0.02$ & $1.47 \pm 0.02$ \\
\hline Finisher (4 to $5 \mathrm{wk}$ ) & $2.13^{\mathrm{a}} \pm 0.08$ & $1.93^{\mathrm{b}} \pm 0.03$ & $1.87^{\mathrm{b}} \pm 0.07$ & $1.95^{\mathrm{ab}} \pm 0.04$ \\
\hline Total (0 to $5 \mathrm{wk})$ & $1.74^{\mathrm{a}} \pm 0.02$ & $1.67^{\mathrm{ab}} \pm 0.01$ & $1.65^{\mathrm{b}} \pm 0.04$ & $1.68^{\mathrm{ab}} \pm 0.02$ \\
\hline
\end{tabular}

${ }_{\mathrm{a}, \mathrm{b}}$ Values with different superscripts in the same row differ significantly $(\mathrm{p}<0.05)$.

$\mathrm{NC}=$ Negative control (basal diet) $\mathrm{PC}=$ Positive control (basal diet with $0.005 \%$ Chlortetracycline); ACP = Alisma canaliculatum with probiotics 
Table 4. Effect of Alisma canaliculatum with probiotics on broiler meat composition ( $\mathrm{n}=15$ for each treatment)

\begin{tabular}{|c|c|c|c|c|}
\hline \multirow{2}{*}{ Parameter } & \multicolumn{4}{|c|}{ Treatments } \\
\hline & $\mathrm{NC}$ & $\mathrm{PC}$ & ACP- $0.5 \%$ & $\mathrm{ACP}-1 \%$ \\
\hline \multicolumn{5}{|l|}{ Breast meat (\%) } \\
\hline Moisture & $74.11 \pm 0.24$ & $73.93 \pm 0.25$ & $73.37 \pm 0.28$ & $73.95 \pm 0.13$ \\
\hline Crude ash & $1.46 \pm 0.07$ & $1.42 \pm 0.11$ & $1.41 \pm 0.06$ & $1.31 \pm 0.06$ \\
\hline Crude fat & $0.29 \pm 0.08$ & $0.26 \pm 0.03$ & $0.28 \pm 0.04$ & $0.26 \pm 0.09$ \\
\hline Crude protein & $24.14^{\mathrm{b}} \pm 0.22$ & $24.39^{\mathrm{ab}} \pm 0.28$ & $24.95^{\mathrm{a}} \pm 0.26$ & $24.49^{\mathrm{ab}} \pm 0.13$ \\
\hline \multicolumn{5}{|l|}{ Thigh meat (\%) } \\
\hline Moisture & $76.43 \pm 0.24$ & $76.65 \pm 0.23$ & $76.54 \pm 0.56$ & $76.86 \pm 0.23$ \\
\hline Crude ash & $1.24 \pm 0.04$ & $1.19 \pm 0.07$ & $1.18 \pm 0.04$ & $1.18 \pm 0.04$ \\
\hline Crude fat & $0.76^{\mathrm{a}} \pm 0.06$ & $0.45^{\mathrm{b}} \pm 0.02$ & $0.42^{\mathrm{b}} \pm 0.02$ & $0.47^{\mathrm{b}} \pm 0.08$ \\
\hline Crude protein & $21.58 \pm 0.20$ & $21.72 \pm 0.18$ & $21.86 \pm 0.55$ & $21.49 \pm 0.23$ \\
\hline
\end{tabular}

${ }^{\mathrm{a}, \mathrm{b}}$ Values with different superscripts in the same row differ significantly $(\mathrm{p}<0.05)$.

$\mathrm{NC}=$ Negative control (basal diet); $\mathrm{PC}=$ Positive control (basal diet with $0.005 \%$ Chlortetracycline) ACP = Alisma canaliculatum with probiotics .

Meat composition, meat yield, and internal organ development

ACP- $0.5 \%$ diet increased $(\mathrm{p}<0.05)$ crude protein content in breast meat compared to the NC group (Table 4). In thigh meat, crude fat content was lower $(p<0.05)$ in the supplemented groups compared to the NC group. Breast meat absolute and relative weights (in relation to body weight) were higher $(\mathrm{p}<0.05)$ in the supplemented groups compared to the NC group (Figure 1). Table 5 shows that ACP diets increased $(\mathrm{p}<0.05)$ gizzard weight compared to the other diets. Further, kidney weight decreased $(\mathrm{p}<0.05)$ in the ACP-1\% group, whereas the supplemented groups had a lower $(\mathrm{p}<0.05)$ large intestine weight compared to the NC group.

Supplementation of ACP at $0.5 \%$ increased the crude protein content in breast meat and decreased crude fat content in thigh meat. This finding is consistent with studies by Hossain et al. (2011a) and Sarker et al. (2010a), who reported higher crude protein content in breast meat of ACP (0.5\%)-fed broilers. However, Hossain et al. (2011a, b) observed lower crude protein content in thigh meat of broilers that consumed a diet containing $0.5 \%$ and $1 \%$ ACP. In a recent report, Kim et al. (2011) noted that $\mathrm{AC}$ is able to decrease the crude protein content of broiler breast meat. Reduction of crude fat content by supplementation of ACP was also reported in broiler breast meat (Hossain et al., 2011a) and pork loin meat (Kim et al., 2010). Therefore, the observed increase in crude protein content and decrease in crude fat content in the ACP- $0.5 \%$ group was possibly an associative effect between the probiotic metabolites and AC components on protein and lipid digestion and metabolism.

Supplementation of ACP increased gizzard relative weight but decreased large intestine weight, although a higher level (1\%) of ACP had a negative effect on kidney weight. Increased gizzard weight (Hossain et al., 2011b) and decreased kidney weight (Hossain et al., 2011a) have also been reported upon supplementation of ACP to broiler diets. However, Kim et al. (2011) observed decreased

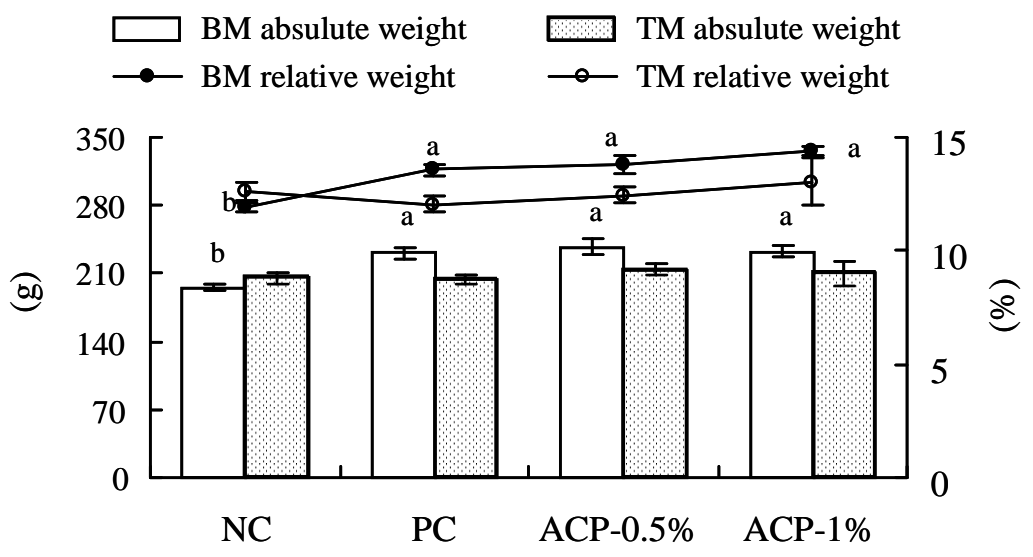

Figure 1. Effect of Alisma canaliculatum with probiotics on breast meat (BM) and thigh meat (TM) absolute and relative weights of broilers ( $\mathrm{n}=15$ for each treatment). Data are presented as the mean \pm SE. Bars and lines not sharing a common letter are significantly different $(\mathrm{p}<0.05) . \mathrm{NC}=$ Negative control (basal diet); $\mathrm{PC}=$ Positive control (basal diet with $0.005 \%$ Chlortetracycline); ACP $=$ Alisma canaliculatum with probiotics. 
Table 5. Effect of Alisma canaliculatum with probiotics on relative internal organ weights of broilers (percentage in relation to body weight) ( $\mathrm{n}=15$ for each treatment)

\begin{tabular}{llllc}
\hline Parameter & \multicolumn{3}{c}{ Treatments } \\
\cline { 2 - 5 } & \multicolumn{1}{c}{$\mathrm{NC}$} & $\mathrm{PC}$ & ACP-0.5\% & ACP-1\% \\
\hline Crop & $0.41 \pm 0.03$ & $0.39 \pm 0.04$ & $0.47 \pm 0.07$ & $0.44 \pm 0.12$ \\
Proventriculus & $0.34 \pm 0.02$ & $0.36 \pm 0.02$ & $0.40 \pm 0.07$ & $0.46 \pm 0.01$ \\
Heart & $0.47 \pm 0.03$ & $0.45 \pm 0.04$ & $0.51 \pm 0.03$ & $0.43 \pm 0.04$ \\
Liver & $1.76 \pm 0.07$ & $1.59 \pm 0.12$ & $1.57 \pm 0.17$ & $1.54 \pm 0.10$ \\
Gizzard & $1.06^{\mathrm{b}} \pm 0.04$ & $1.01^{\mathrm{b}} \pm 0.03$ & $1.25^{\mathrm{a}} \pm 0.08$ & $1.27^{\mathrm{a}} \pm 0.03$ \\
Pancreas & $0.15 \pm 0.01$ & $0.16 \pm 0.01$ & $0.17 \pm 0.02$ & $0.15 \pm 0.01$ \\
Kidney & $0.65^{\mathrm{a}} \pm 0.02$ & $0.62^{\mathrm{a}} \pm 0.02$ & $0.58^{\mathrm{a}} \pm 0.05$ & $0.53^{\mathrm{b}} \pm 0.03$ \\
Small intestine & $1.97 \pm 0.13$ & $2.14 \pm 0.11$ & $2.08 \pm 0.07$ & $2.17 \pm 0.25$ \\
Large intestine & $0.19^{\mathrm{a}} \pm 0.03$ & $0.12^{\mathrm{b}} \pm 0.02$ & $0.12^{\mathrm{b}} \pm 0.01$ & $0.11^{\mathrm{b}} \pm 0.02$ \\
Ceca & $0.42 \pm 0.05$ & $0.30 \pm 0.03$ & $0.39 \pm 0.03$ & $0.40 \pm 0.06$ \\
Abdominal fat & $1.81 \pm 0.13$ & $2.14 \pm 0.33$ & $2.06 \pm 0.30$ & $1.99 \pm 0.13$ \\
\hline
\end{tabular}

a,b Values with different superscripts in the same row differ significantly $(\mathrm{p}<0.05)$.

$\mathrm{NC}=$ Negative control (basal diet) $; \mathrm{PC}=$ Positive control (basal diet with $0.005 \%$ Chlortetracycline); ACP = Alisma canaliculatum with probiotics

gizzard weight in AC-fed broilers. However, there have been no reported changes in the relative weights of internal organs from broilers fed Lactobacillus spp. and medicinal plants (Hernandez et al., 2004; Awad et al., 2009). Further, addition of ACP to broiler diets increased breast meat absolute and relative weights. To the best of our knowledge, no other studies are available for comparison. Vikari (2008) reported a $7.9 \%$ breast meat yield advantage using plant extract supplementation as opposed to antibiotic treatment. However, Garcia et al. (2007) previously observed that meat yield was not affected by the plant extracts. Previous studies indicated that probiotics had a positive effect on
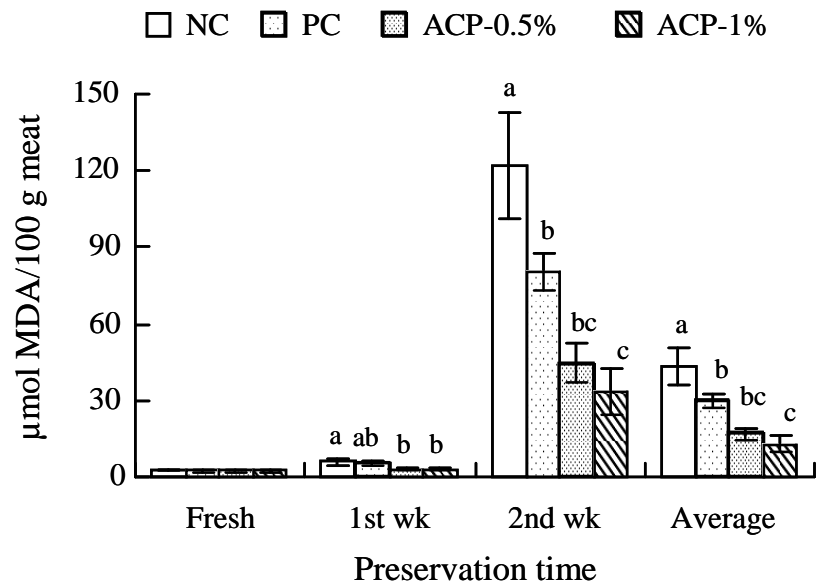

Figure 2. Effect of Alisma canaliculatum with probiotics on thiobarbituric acid reactive substance (TBARS) values of breast meat ( $\mathrm{n}=15$ for each treatment). TBARS values are expressed as micromoles of malondialdehyde (MDA) per $100 \mathrm{~g}$ of meat. Data are presented as the mean \pm SE. Bars within a time class not sharing a common letter are significantly different $(\mathrm{p}<0.05)$. $\mathrm{NC}=$ Negative control (basal diet); $\mathrm{PC}=$ Positive control (basal diet with $0.005 \%$ Chlortetracycline); $\mathrm{ACP}=$ Alisma canaliculatum with probiotics. broiler meat yield. Fidler et al. (2003) reported higher breast meat yield in a probiotic-supplemented group, whereas Pelicano et al. (2003) observed that broilers fed probiotics showed higher thigh yield at 45 days of age. The increase in breast muscle weight in the ACP groups indicates a possible effect of the plant constituents and probiotic preparations on the production of musculature in broilers.

\section{Oxidative stability of meat}

Supplementation of ACP had an effect on the oxidative stability of meat (Figures 2 and 3). ACP groups had lower $(\mathrm{p}<0.05)$ TBARS values after wks 1 and 2 of preservation

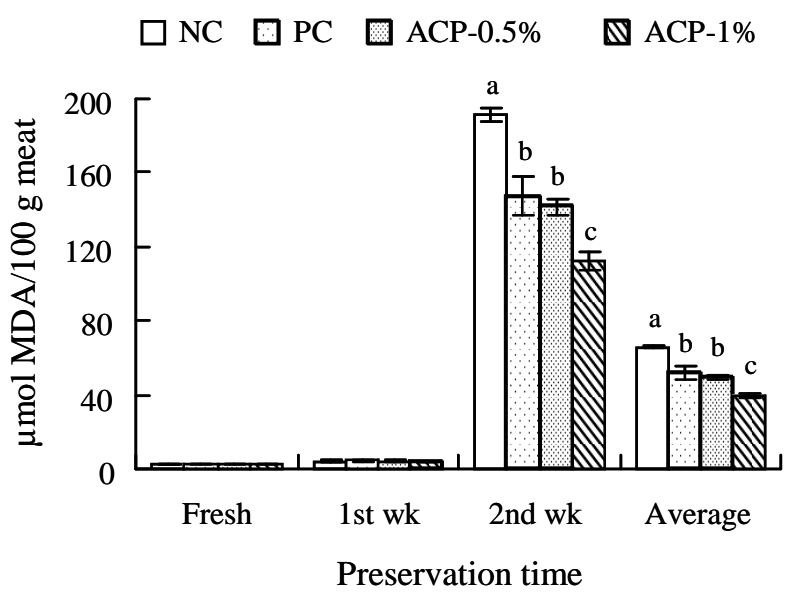

Figure 3. Effect of Alisma canaliculatum with probiotics on thiobarbituric acid reactive substance (TBARS) values of thigh meat ( $\mathrm{n}=15$ for each treatment). TBARS values are expressed as micromoles of malondialdehyde (MDA) per $100 \mathrm{~g}$ of meat. Data are presented as the mean \pm SE. Bars within a time class not sharing a common letter are significantly different $(\mathrm{p}<0.05)$. $\mathrm{NC}=$ Negative control (basal diet); $\mathrm{PC}=$ Positive control (basal diet with $0.005 \%$ Chlortetracycline); ACP $=$ Alisma canaliculatum with probiotics. 
Table 6. Effect of Alisma canaliculatum with probiotics on fatty acid composition of breast meat $(\mathrm{g} / 100 \mathrm{~g}$ total fat) $(\mathrm{n}=15$ for each treatment)

\begin{tabular}{|c|c|c|c|c|}
\hline \multirow{2}{*}{ Parameter $^{1}$} & \multicolumn{4}{|c|}{ Treatments } \\
\hline & $\mathrm{NC}$ & $\mathrm{PC}$ & ACP- $0.5 \%$ & ACP- $1 \%$ \\
\hline Myristic acid (C14:0) & $0.65 \pm 0.02$ & $0.69 \pm 0.12$ & $0.69 \pm 0.03$ & $0.70 \pm 0.02$ \\
\hline Palmitic acid (C16:0) & $25.03 \pm 0.43$ & $25.12 \pm 0.61$ & $25.30 \pm 0.38$ & $25.46 \pm 0.26$ \\
\hline Palmitoleic acid (C16:1n7) & $4.53 \pm 0.15$ & $4.40 \pm 0.26$ & $4.91 \pm 0.16$ & $4.90 \pm 0.46$ \\
\hline Stearic acid (C18:0) & $13.88 \pm 0.47$ & $13.78 \pm 0.65$ & $13.68 \pm 0.40$ & $13.32 \pm 0.45$ \\
\hline Oleic acid $(\mathrm{C} 18: 1 \mathrm{n} 9)$ & $37.55 \pm 0.63$ & $37.45 \pm 0.49$ & $39.62 \pm 0.45$ & $38.25 \pm 0.52$ \\
\hline Linoleic acid (C18:2n6) & $10.98 \pm 0.17$ & $10.71 \pm 0.25$ & $10.44 \pm 0.42$ & $10.33 \pm 0.14$ \\
\hline$\alpha$-linolenic acid (C18:3n3) & $0.73 \pm 0.06$ & $0.88 \pm 0.07$ & $0.88 \pm 0.16$ & $0.84 \pm 0.10$ \\
\hline Eicosenoic acid (C20:1n9) & $2.53 \pm 0.23$ & $2.93 \pm 0.32$ & $2.47 \pm 0.39$ & $3.01 \pm 0.37$ \\
\hline Arachidonic acid (C:20:4n6) & $2.39^{\mathrm{a}} \pm 0.24$ & $2.14^{\mathrm{ab}} \pm 0.07$ & $1.57^{\mathrm{b}} \pm 0.23$ & $1.60^{\mathrm{b}} \pm 0.19$ \\
\hline Eicosapentaenoic acid (C20:5n3) & $0.46 \pm 0.01$ & $0.53 \pm 0.07$ & $0.52 \pm 0.06$ & $0.63 \pm 0.15$ \\
\hline Docosahexaenoic acid (C22:6n3) & $1.25^{\mathrm{a}} \pm 0.04$ & $1.40^{\mathrm{a}} \pm 0.15$ & $0.92^{\mathrm{b}} \pm 0.06$ & $0.96^{\mathrm{b}} \pm 0.03$ \\
\hline SFA & $39.57 \pm 0.67$ & $39.59 \pm 0.71$ & $39.67 \pm 0.32$ & $39.48 \pm 0.61$ \\
\hline MUFA & $44.62 \pm 0.70$ & $44.78 \pm 0.44$ & $46.00 \pm 0.52$ & $46.17 \pm 0.68$ \\
\hline PUFA & $15.81^{\mathrm{a}} \pm 0.42$ & $15.64^{\mathrm{a}} \pm 0.31$ & $14.34^{\mathrm{b}} \pm 0.32$ & $14.36^{\mathrm{b}} \pm 0.36$ \\
\hline PUFA/SFA & $0.40 \pm 0.02$ & $0.39 \pm 0.01$ & $0.36 \pm 0.01$ & $0.36 \pm 0.01$ \\
\hline UFA/SFA & $1.53 \pm 0.04$ & $1.53 \pm 0.05$ & $1.52 \pm 0.02$ & $1.55 \pm 0.01$ \\
\hline n3 & $2.44 \pm 0.03$ & $2.80 \pm 0.19$ & $2.32 \pm 0.17$ & $2.43 \pm 0.25$ \\
\hline n6 & $13.37^{\mathrm{a}} \pm 0.41$ & $12.84^{\mathrm{ab}} \pm 0.23$ & $12.01^{\mathrm{b}} \pm 0.34$ & $11.93^{\mathrm{b}} \pm 0.15$ \\
\hline $\mathrm{n} 6 / \mathrm{n} 3$ & $5.47 \pm 0.16$ & $4.65 \pm 0.29$ & $5.25 \pm 0.43$ & $5.04 \pm 0.45$ \\
\hline
\end{tabular}

a,b Values with different superscripts in the same row differ significantly $(\mathrm{p}<0.05)$.

$\mathrm{NC}=$ Negative control (basal diet); PC = Positive control (basal diet with 0.005\% Chlortetracycline); ACP = Alisma canaliculatum with probiotics .

${ }^{1}$ SFA = Saturated fatty acids; MUFA = Monounsaturated fatty acids; PUFA = Polyunsaturated fatty acids; $\mathrm{n} 3=$ Total omega 3 fatty acid; n6 = Total omega 6 fatty acid.

as well as average values in breast and thigh meat compare to $\mathrm{NC}$ group. In terms of TBARS values among the supplemented groups, the ACP- $0.5 \%$ group was not significantly different from the PC group, whereas the $\mathrm{ACP}-1 \%$ group had the lowest $(\mathrm{p}<0.05)$ values.

Lipid oxidation is one of the primary mechanisms of quality deterioration in meat products through adverse changes in flavor, color, texture, and nutritive value (Ura et al., 2008). The TBARS test is the most widely used method for quantifying lipid oxidation development in meat and meat products. The results from the TBARS test provided evidence that ACP supplementation could improve oxidative stability in broiler meat. This finding is consistent with studies by Hossain et al. (2011b) and Sarker et al. (2010a), who found lower TBARS values in ACPsupplemented broiler meat. However, Hossain et al. (2011a) observed no changes after 1 week of preservation. The antioxidant activity of plant extracts is mainly related to the presence of phenolic compounds. Moreover, compounds such as flavonoids and terpenoids also present antioxidant activity (Rizzo et al., 2008). In addition, antioxidative activities have been reported in probiotic strains such as Saccharomyces cerevisiae by Zhang et al. (2005). Further, $\mathrm{AC}$ or its constituents have been reported to possess potent antioxidant properties (Choi, 2004). Hur et al. (2007) reported that methanol extract of $A$. orientale rhizome can enhance the activities of hepatic antioxidant enzymes such as epoxide hydrolase and glutathione S-transferase. These substances may intercept and neutralize free radicals, preventing propagation of the oxidation process.

\section{Fatty acid composition of meat}

Fatty acid compositions of breast and thigh meats are shown in Table 6 and 7. ACP groups had lower $(\mathrm{p}<0.05)$ arachidonic acid and total $\mathrm{n} 6$ fatty acid contents in breast meat compared to the NC group. Docosahexaenoic acid and PUFA contents were also lower $(p<0.05)$ in the ACP groups compared to the $\mathrm{NC}$ and PC groups. In thigh meat, content of palmitoleic acid increased in the ACP-1\% group, whereas that of docosahexaenoic acid decreased in the ACP- $0.5 \%$ group compared to the $\mathrm{NC}$ group $(\mathrm{p}<0.05)$. NC group had higher $(\mathrm{p}<0.05)$ linoleic acid, PUFA, PUFA/SFA, and $n 6$ fatty acid contents compared to the other groups. Although PUFA and n6 fatty acid contents changed, the UFA/SFA and $n 6 / n 3$ ratios were unaffected $(p>0.05)$ in both breast and thigh meats.

In terms of human health, the fatty acid composition of meat products is an important parameter of meat quality. Further, the role of the PUFA/SFA ratio for this purpose has decreased while that of the total $n 6 / n 3$ ratio has increased 
Table 7. Effect of Alisma canaliculatum with probiotics on fatty acid composition of thigh meat $(\mathrm{g} / 100 \mathrm{~g}$ total fat) ( $\mathrm{n}=15$ for each treatment)

\begin{tabular}{|c|c|c|c|c|}
\hline \multirow{2}{*}{ Parameter $^{1}$} & \multicolumn{4}{|c|}{ Treatments } \\
\hline & $\mathrm{NC}$ & $\mathrm{PC}$ & ACP- $0.5 \%$ & $\mathrm{ACP}-1 \%$ \\
\hline Myristic acid (C14:0) & $0.81 \pm 0.37$ & $0.85 \pm 0.04$ & $0.83 \pm 0.03$ & $0.82 \pm 0.02$ \\
\hline Palmitic acid (C16:0) & $24.19 \pm 0.82$ & $25.32 \pm 0.52$ & $25.06 \pm 0.47$ & $24.68 \pm 0.38$ \\
\hline Palmitoleic acid (C16:1n7) & $5.74^{\mathrm{b}} \pm 0.21$ & $6.58^{\mathrm{a}} \pm 0.10$ & $6.21^{\mathrm{ab}} \pm 0.24$ & $6.99^{\mathrm{a}} \pm 0.41$ \\
\hline Stearic acid (C18:0) & $13.88 \pm 0.76$ & $14.16 \pm 0.73$ & $13.66 \pm 0.85$ & $13.76 \pm 0.38$ \\
\hline Oleic acid (C18:1n9) & $39.54 \pm 1.16$ & $40.15 \pm 0.62$ & $40.76 \pm 0.66$ & $40.55 \pm 0.40$ \\
\hline Linoleic acid (C18:2n6) & $11.63^{\mathrm{a}} \pm 0.47$ & $9.20^{\mathrm{b}} \pm 0.26$ & $9.98^{\mathrm{b}} \pm 0.56$ & $9.46^{\mathrm{b}} \pm 0.33$ \\
\hline$\alpha$-linolenic acid (C18:3n3) & $0.65 \pm 0.05$ & $0.51 \pm 0.04$ & $0.61 \pm 0.03$ & $0.60 \pm 0.11$ \\
\hline Eicosenoic acid (C20:1n9) & $1.56 \pm 0.05$ & $1.49 \pm 0.11$ & $1.35 \pm 0.06$ & $1.43 \pm 0.20$ \\
\hline Arachidonic acid (C:20:4n6) & $1.03 \pm 0.18$ & $0.94 \pm 0.07$ & $0.93 \pm 0.12$ & $0.89 \pm 0.11$ \\
\hline Eicosapentaenoic acid (C20:5n3) & $0.25 \pm 0.03$ & $0.24 \pm 0.03$ & $0.24 \pm 0.04$ & $0.30 \pm 0.09$ \\
\hline Docosahexaenoic acid (C22:6n3) & $0.74^{\mathrm{a}} \pm 0.09$ & $0.59^{\mathrm{ab}} \pm 0.06$ & $0.41^{\mathrm{b}} \pm 0.08$ & $0.54^{\mathrm{ab}} \pm 0.04$ \\
\hline SFA & $38.87 \pm 0.64$ & $40.32 \pm 0.41$ & $39.54 \pm 0.51$ & $39.25 \pm 0.17$ \\
\hline MUFA & $46.83 \pm 1.01$ & $48.22 \pm 0.68$ & $48.31 \pm 0.74$ & $48.96 \pm 0.39$ \\
\hline PUFA & $14.29^{\mathrm{a}} \pm 0.71$ & $11.47^{\mathrm{b}} \pm 0.31$ & $12.15^{\mathrm{b}} \pm 0.65$ & $11.79^{\mathrm{b}} \pm 0.55$ \\
\hline PUFA/SFA & $0.37^{\mathrm{a}} \pm 0.02$ & $0.29^{\mathrm{b}} \pm 0.01$ & $0.31^{\mathrm{b}} \pm 0.02$ & $0.30^{\mathrm{b}} \pm 0.02$ \\
\hline UFA/SFA & $1.58 \pm 0.04$ & $1.48 \pm 0.03$ & $1.53 \pm 0.03$ & $1.55 \pm 0.01$ \\
\hline n3 & $1.64 \pm 0.15$ & $1.33 \pm 0.05$ & $1.25 \pm 0.10$ & $1.44 \pm 0.22$ \\
\hline n6 & $12.66^{\mathrm{a}} \pm 0.63$ & $10.14^{\mathrm{b}} \pm 0.03$ & $10.90^{\mathrm{b}} \pm 0.58$ & $10.35^{\mathrm{b}} \pm 0.40$ \\
\hline n6/n3 & $7.90 \pm 0.68$ & $7.66 \pm 0.42$ & $8.83 \pm 0.61$ & $7.68 \pm 1.01$ \\
\hline
\end{tabular}

a,b Values with different superscripts in the same row differ significantly $(\mathrm{p}<0.05)$.

$\mathrm{NC}=$ Negative control (basal diet); PC = Positive control (basal diet with 0.005\% Chlortetracycline); ACP = Alisma canaliculatum with probiotics .

${ }^{1}$ SFA = Saturated fatty acids; MUFA = Monounsaturated fatty acids; PUFA = Polyunsaturated fatty acids; n3 = Total omega 3 fatty acid; n6 = Total omega 6 fatty acid.

(Dublecz et al., 2004). Upon supplementation of ACP, the levels of arachidonic acid and docosahexaenoic acid decreased, which affected the PUFA and total n6 fatty acid contents of breast meat. On the other hand, reduction of linoleic acid content led to decreased levels of PUFA, PUFA/SFA, and total n6 fatty acids in thigh meat. These results suggest that ACP has an effect on fat metabolism. This finding coincides with Hossain et al. (2011b), who reported lower PUFA and total n6 fatty acid contents in ACP (1\%)-fed broiler meat featuring rhizome. Nevertheless, Kim et al. (2011) found higher linoleic acid and lower arachidonic acid contents in breast meat upon supplementation with AC $(0.5 \%)$, but no changes in PUFA content. Alteration of PUFA and total n6 fatty acid levels had no influences the UFA/SFA or $n 6 / \mathrm{n} 3$ ratio in both breast and thigh meats in this study. It is well accepted that the inclusion of probiotics such as Saccharomyces can increase the linolenic acid content and UFA/SFA ratio in pectoral meat of broilers through a positive effect on the intestinal flora (Endo et al., 1999). However, Hossain et al. (2011a) observed that ACP $(0.5 \%)$ diet is able to increase PUFA and total $\mathrm{n} 3$ fatty acid contents in broiler meat, resulting in a decreased $n 6 / n 3$ ratio. As we have no information about the fatty acid composition of $\mathrm{AC}$ and $\mathrm{ACP}$, it is evident that the fatty acid composition of the feed is the most important determinant of the fatty acid composition of the resulting broiler breast and thigh meats (Cortinas et al., 2004). The inconsistent results could be attributed to the species, strains, and survivability of the probiotic microorganisms, in addition to the plant bioactive components, plant fatty acid profile, and dietary supplementation levels.

\section{CONCLUSIONS}

Plant extracts present some advantages compared to traditional antimicrobials as the latter have a single active principle. Since probiotic microbes have different beneficial properties, an optimal product may require a combination of several strains. ACP tested in this study was a combination of A. canaliculatum and multi probiotic strains, and exhibited a high tolerance to acid, bile, and heat. Results indicated that ACP- $0.5 \%$ diet increased body weight, improved FCR, and had a positive effect on carcass composition. It also increased gizzard relative weight but had no negative effect on kidney relative weight. Supplementation of ACP improved oxidative stability of both breast and thigh meats, although it affected fatty acid composition. Future studies are needed to ascertain the fatty acid metabolism of AC and ACP. Therefore, broiler producers can incorporate $\mathrm{ACP}$ at a level of $0.5 \%$ into the 
broiler diets as a potential feed additive.

\section{ACKNOWLEDGEMENTS}

The research was supported by Bio-industry Technology Development Program under Ministry of Food, Agriculture, Forestry, and Fisheries, Republic of Korea.

\section{REFERENCES}

Ahmad, I. 2006. Effect of probiotics on broilers performance. Int. J. Poult. Sci. 5:593-597.

AOAC. 2000. Official methods of analysis. 17th edn. Association of Official Analytical Chemists, Washington, DC, USA.

Awad, W. A., K. Ghareeb, S. Abdel-Raheem and J. Böhm. 2009. Effects of dietary inclusion of probiotic and synbiotic on growth performance, organ weights, and intestinal histomorphology of broiler chickens. Poult. Sci. 88:49-55.

Choe, M., D. J. Kim, H. J. Lee, J. K. You, D. J. Seo, J. H. Lee and M. J. Chung. 2008. A study on the glucose-regulating enzymes and antioxidant activities of water extracts from medicinal herbs. J. Korean Soc. Food Sci. Nutr. 37:542-547.

Choi, S. S. 2004. The effects of Alisma canaliculatum butanol fraction with selenium on glycogen level, lipid metabolism and lipid peroxidation in streptozotocin-induced diabetic rats. Korean J. Nutr. 37:15-22.

Cortinas, L., A. Barroeta, C. Villaverde, J. Galobart, F. Guardiola and M. D. Baucells. 2005. Influence of the dietary polyunsaturation level on chicken meat quality: Lipid oxidation. Poult. Sci. 84:48-55.

Cross, D. E., R. M. Mcdevitt, K. Hillman and T. Acamovic. 2007. The effect of herbs and their associated essential oils on performance, dietary digestibility and gut microflora in chickens from 7 to 28 days of age. Br. Poult. Sci. 48:496-506.

Dublecz, K., A. Bartos, L. Pal, L. Wagner, A. Banyai, S. Toth and G. Babinszki. 2004. Modification the fatty acid composition of different tissues in broiler chicks. Proceedings of the XXII World's Poultry Congress. Istanbul, Turkey. p. 424.

Endo, J. and M. Nakano. 1999. Influence of a probiotic on productivity, meat components, lipid metabolism, caecal flora and metabolites, and raising environment in broiler production. Anim. Sci. J. 70:207-218.

Fidler, D. J., B. George, C. L. Quarles and M. T. Kidd. 2003. Broiler performance and carcass traits as affected by dietary liquid Saccharopolyspora solubles concentrate. J. Appl. Poult. Res. 12:153-159.

Fuller, R. 1992. History and development of probiotics. In: Probiotics-The Scientific Basis (Ed. R. Fuller). Chapman and Hall, London. pp. 1-8.

Garcia, V., P. Cotala-Gregori, F. Hernandez, M. D. Megias and J. Madrid. 2007. Effect of formic acid and plant extracts on growth, nutrient digestibility, intestine mucosa morphology and meat yield of broilers. J. Appl. Poult. Res. 16:558-563.

Guerra, N. P., P. F. Bernardez, J. Mensez, P. Cachaldora and L. P. Castro. 2007. Production of four potentially probiotic lactic acid bacteria and their evaluation as feed additives for weaned piglets. Anim. Feed Sci. Technol. 134:89-107.

Hernandez, F., J. Madrid, V. Garcia, J. Orengo and M. D. Megias.
2004. Influence of two plant extracts on broilers performance, digestibility, and digestive organ size. Poult. Sci. 83:169-174.

Hong, X., H. Tang, L. Wu and L. Li. 2006. Protective effects of the Alisma orientalis extract on the experimental nonalcoholic fatty liver disease. J. Pharm. Pharmacol. 58:1391-1398.

Hossain, M. E., S. Y. Ko, G. M. Kim, J. D. Firman and C. J. Yang. 2011a. Water plantain (Alisma canaliculatum) probiotics as an alternative feed additive for broiler. Poult. Sci. 90 (E-Suppl. 1): 14 .

Hossain, M. E., G. M. Kim, H. Ji and C. J. Yang. 2011b. Comparison of two medicinal plant probiotics on broiler performances and meat quality. In: Proceeding of the 18th European Symposium on Poultry Nutrition, Izmir, Turkey. pp. 329-332.

Huang, Y. T., D. M. Huang, S. C. Chueh, C. M. Teng and J. H. Guh. 2006. Alisol B acetate, a triterpene from Alismatis rhizoma, induced Bax nuclear translocation and apoptosis in human hormone-resistant prostate cancer PC-3 cells. Cancer Lett. 231:270-278.

Hur, J. M., J. W. Choi and J. C. Park. 2007. Effects of methanol extract of Alisma orientale rhizome and its major component, alisol b 23-acetate, on hepatic drug metabolizing enzymes in rats treated with bromobenzene. Arch. Pharm. Res. 30:15431549.

Jun, K. D., H. J. Kim, K. H. Lee, H. D. Paik and J. S. Kang. 2002. Characterization of Bacillus polyfermenticus SCD as a probiotic. Korean J. Microbiol. Biotechnol. 30:359-366.

Kang, D. G., E. J. Sohn, M. K. Moon, Y. J. Mun, W. H. Woo, M. K. Kim and H. S. Lee. 2006. Yukmijihwang-tang ameliorates ischemia/reperfusion-induced renal injury in rats. $\mathrm{J}$. Ethnopharmacol. 104:47-53.

Kim, D. W., S. H. Kim, D. J. Yu, G. H. Kang, J. H. Kim, H. G. Kang, B. G. Jang, J. C. Na, O. S. Suh, I. S. Jang and K. S. Lee. 2007. Effects of single or mixed supplements of plant extract, fermented medicinal plants and Lactobacillus on growth performance in broilers. Korean J. Poult. Sci. 34:187-196.

Kim, K. S., G. M. Kim, M. E. Hossain, S. W. Park and C. J. Yang. 2010. Effect of Alisma canaliculatum, Viscum albumas and Cornus officinalis probiotics feed additives on growth performance and immunity in growing pigs. In: Proceeding of the Annual Congress of Korean Society of Animal Sciences and Technology, Jinju. South Korea. p. 217.

Kim, K. S., G. M. Kim, H. Ji, S. U. Park and C. J. Yang. 2011. Effect of dietary supplementation of Alisma canaliculatum (Alismatis rhizoma) and Viscum album (mistletoe) on growth performance and immunity in broiler chicken. Korean J. Poult. Sci. 38:21-28.

Kim, M. W. 2003. Effects are of butanol fraction of Alisma canaliculatum and of selenium on blood glucose levels and lipid metabolism in streptozotocin-induced diabetic rats. Nutr. Sci. 6:85-93.

Kobayashi, Y., K. Tohyama and T. Terashima. 1974. Studies on biological characteristics of Lactobacillus: II. Tolerance of the multiple antibiotic resistance-strain, $L$. casei PSR 3002, to artificial digestive fluids. Jpn. J. Microbiol. 29:691-697.

Kubo, M., H. Matsuda, N. Tomohiro and M. Yoshikawa. 1997. Studies on Alismatis rhizoma. I. Anti-allergic effects of methanol extract and six terpene components from Alismatis rhizome (dried rhizome of Alisma orientale). Biol. Pharm. Bull. 
20:511-516.

Lee, S. M., J. H. Kim, Y. Zhang, R. B. An, B. S. Min, H. Joung and H. K. Lee. 2003. Anti-complementary activity of protostane-type triterpenes from Alismatis rhizoma. Arch. Pharm. Res. 26:463-465.

Lee, S. O., S. Y. Kim, S. M. Han, H. M. Kim, S. S. Ham and I. J. Kang, 2006. Corni fructus scavenges hydroxy radicals and decreases oxidative stress in endothelial cells. J. Med. Food. 9:594-598.

Matsuda, H., T. Kageura, T. Murakami, A. Kishi and M. Yoshikawa. 1999. Effects of sesquiterpenes and triterpenes from the rhizome of Alisma orientale on nitric oxide production in lipopolysaccharide-activated macrophages: absolute stereostructures of alismaketones-B 23-acetate and -C 23-acetate. Bioorg. Med. Chem. Lett. 9:3081-3086.

Mikamo, H., K. Kawazoe, K. Izumi, Y. Sato and T. Tamaya. 1998. Effects of crude herbal ingredients on intrauterine infection in a rat model. Curr. Ther. Res. 59:122-127.

Mountzouris, K. C., P. Tsirtsikos, E. Kalamara, S. Nitsch, G. Schatzmayr and K. Fegeros. 2007. Evaluation of the efficacy of a probiotic containing Lactobacillus, Bifidobacterium, Enterococcus, and Pediococcus strains in promoting broiler performance and modulating cecal microflora composition and metabolic activities. Poult. Sci. 86:309-317.

Mountzouris, K. C., P. Tsitrsikos, I. Palamidi, A. Arvaniti, M. Mohnl, G. Schatzmayr and K. Fegeros. 2010. Effects of probiotic inclusion levels in broiler nutrition on growth performance, nutrient digestibility, plasma immunoglobulins, and cecal microflora composition. Poult. Sci. 89:58-67.

Nakajima, Y., Y. Satoh, M. Katsumata, K. Tsujiyama, M. Ida and J. Shoji. 1994. Terpenoids of Alisma orientale rhizomes and the crude drug Alismatis rhizoma. Phytochem. 36:119-127.

National Research Council. 1994. Nutrient requirements of poultry. 9th rev. edn. National Academy Press, Washington, DC, USA.

Ndlovu, T., M. Chimonyo, A. I. Okoh, V. Muchenje, K. Dzama and J. G. Raats. 2007. Assessing the nutritional status of beef cattle: current practices and future prospects. Afr. J. Biotechnol. 6:2727-2734.

NRLSI. 2002. Food composition table. 6th rev. edn. National Rural Living Science Institute. Rural Development Administration, South Korea.

Park, H. S. 1999. Development of multi-probiotics. The final report of ministry of agriculture and forestry research and development project, South Korea.

Pelicano, E. R. L., P. A. Souza de, H. B. A. Souza de, A. Oba, E. A. Norkus, L. M. Kodawara and T. M. A. Lima de. 2003. Effect of different probiotics on broiler carcass and meat quality. Braz. J. Poult. Sci. 5:207-214.

Peng, G. P. and F. C. Lou. 2002. Isolation and identification of diterpenes from Alisma orientalis Juzep. Acta Pharm. Sin. 37:950-954.

Peng, G. P., G. Tian, X. F. Huang and F. C. Lou. 2003. Guaianetype sesquiterpenoids from Alisma orientalis. Phytochem. 63:877-881.

Peng, G. P., G. Y. Zhu and F. C. Lou. 2002. Terpenoids from Alisma orientalis Juzep. Nat. Prod. Res. Dev. 14:7-10.
Priyankarage, N., S. S. P. Silva, S. P. Gunaratne, H. Kothalawala, M. W. C. D. Palliyaguru and G. A. Gunawardana. 2003. Efficacy of probiotics and their effects on performance, carcase characteristics, intestinal microflora and Salmonella incidence in broilers. Br. Poult. Sci. 44:S26-S27.

Richards, M. P. 2003. Genetic regulation of feed intake and energy balance in poultry. Poult. Sci. 82:907-916.

Rizzo, P. V., J. F. M. Menten, A. M. C. Racanicci and J. Santarosa. 2008. Foundation and perspectives of the use of plant extracts as performance enhancers in broilers. Braz. J. Poult. Sci. 10:195-204.

Ross Broiler Nutrition Supplement. 2009. Appendix 1: Nutrient Specifications for As-Hatched Broilers Grown $<1.9 \mathrm{~kg}(4.2 \mathrm{lb})$ live weight. pp. 20. Available from: http://en.aviagen.com/ assets/Tech_Center/Ross_Broiler/Ross_Nutrition_Supplement. pdf.

Sarker, M. S. K., G. M. Kim, H. Ji, M. R. E. Park and C. J. Yang. 2010a. Effect of different medicinal plants with probiotics on growth performance and meat composition and lipid oxidation in Ross broilers. In: Proceeding of the Annual Congress of Korean Society of Animal Sciences and Technology, Jinju. South Korea. p. 210.

Sarker, M. S. K., S. Y. Ko, S. M. Lee, G. M. Kim, J. K. Choi and C. J. Yang. 2010b. Effect of different feed additives on growth performance and blood profiles of Korean Hanwoo calves. Asian-Aust. J. Anim. Sci. 23:52-60.

Sarker, M. S. K. and C. J. Yang. 2011. Eosungcho (Houttuynia cordata) with multi strain probiotics as alternative to antibiotic for broiler production. J. Med. Plant Res. 5:4411-4417.

SAS Institute Inc. 2003. SAS user's guide: Version 9.1 edn. SAS Institute Inc., Cary, North Carolina, USA.

Simon, O., A. Jadamus and W. Vahjen. 2001. Probiotic feed additives-effectiveness and expected modes of action. J. Anim. Feed Sci. 10:51-67.

Ura, B., R. Taharnklaew and S. Kijparkorn. 2008. The effects of vitamin $\mathrm{E}$ in crude palm oil on growth performance, lipid peroxidation and tissue vitamin $\mathrm{E}$ concentration in broilers. In: Proceedings of the 7th Chulalongkorn University Veterinary Annual Conference, May 1, 2008.

Vikari, A. 2008. Plant extracts benefit producers and consumers. World Poult. 24:16-17.

Yang, C. J., I. Y. Yang, D. H. Oh, I. H. Bae, S. G. Cho, I. G. Kong, D. Uuganbayar, I. S. Nou and K. S. Choi. 2003. Effect of green tea by-product on performance and body composition in broiler chicks. Asian-Aust. J. Anim. Sci. 16:867-872.

Yoshikawa, M., S. Yamaguchi, H. Matsuda, Y. Kohda, H. Ishikawa, N. Tanaka, J. Yamahara and N. Murakami. 1994. Crude drugs from aquatic plants. IV. On the constituents of Alismatis rhizoma. (2). Stereostructures of bioactive sesquiterpenes, alismol, alismoxide, orientalols $\mathrm{A}, \mathrm{B}$, and $\mathrm{C}$, from Chinese Alismatis rhizoma. Chem. Pharm. Bull. 42:1813-1816.

You, S. J., J. K. Cho, S. G. Hwang and K. C. Heo. 2005. Probiotic characteristics of Lactobacillus rhamnosus isolated from kefir. Korean J. Food Sci. Anim. Resour. 25:357-364.

Zhang, A. W., B. D. Lee, S. K. Lee, K. W. Lee, G. H. An, K. B. Song and C. H. Lee. 2005. Effects of yeast (Saccharomyces cerevisiae) cell components on growth performance, meat quality, and ileal mucosa development of broiler chicks. Poult. Sci. 84:1015-1021. 